\title{
IMPROVEMENT OF POWER SYSTEM PERFORMANCE THROUGH WAVELET NEURAL NETWORK STATIC VAR COMPENSATOR CONTROLLER
}

\author{
Ashraf Mohamed Hemeida Abdel Gawad \\ Electrical Engineering Department, Higher Institute of Energy, South \\ Valley University, Aswan, Egypt
}

(Received July 1, 2006 Accepted August 23, 2006)

\begin{abstract}
This paper aimed to apply a nonlinear hybrid wavelet neural network, WNN controller for static VAR compensators SVC. The proposed WNN control the amount of the reactive power consumed or delivered to the network by controlling the TRC firing angle. Single layer wavelet neural network, WNN model technique is used in the present paper. The proposed controller tracks the power systems response to zero error in the post fault conditions. The proposed controller is applied for sample single machine infinite bus power system. The time simulations indicate the effectiveness, robustness and fast response of the proposed controller in comparison with the conventional one's. The studied system is modeled by nonlinear differential and algebraic equations which solved by the Matlab Software.
\end{abstract}

KEYWORDS: Static VAR Compensators - FACTS - Wavelet neural network - Power system stability.

\section{INTRODUCTION}

The SVC is one of the most important FACTS devices which are very effective for voltage regulations and stability improvement of the power systems. Due to the extensions of the power networks the use of SVC became very essential.

Fixed capacitors, Thyristor control reactors static VAr Compensators SVC are used world wide for utilities purposes. The main objective of inserting such SVC systems is to regulate the node voltages at weak points of the utility grid as well as maintaining the voltage stability of industrial loads[1-6]. However it is also can be used for improving the power system dynamic performance in case of abnormal operating conditions[7-8].

The control system is usually designed based on linearizing the system model around a prescribed operating conditions. The linear regulator theory, direct feed back linearization and exact linearization are usually used. Stabilization process based on these conventional linear control theory with fixed parameters are working very well, and provide a very good damping in a prescribed operating conditions. Such intelligent control techniques has been recently introduced, to be used in power systems such as adaptive neural network, ANN, fuzzy logic FL control, adaptive neuro Fuzzy, expert 
system, genetic algorithms[9-14]. The advantages of these control techniques provide a very effective damping than the conventional control theory, with better control quality and independent of power systems parameters.

The present paper introduces wavelet neural network, WNN controller for static VAR Compensator, which train the data online and independent of the system parameters. The damping effect of the proposed WNN is evaluated in a comparative study with conventional PI controller. The Comparative Study proves the superiority of the proposed controller over the conventional one's with better control quality.

\section{STUDIED SYSTEM FOR FEASIBILITY STUDY}

The studied power system is shown in Fig. 1. The system data is given in [7].

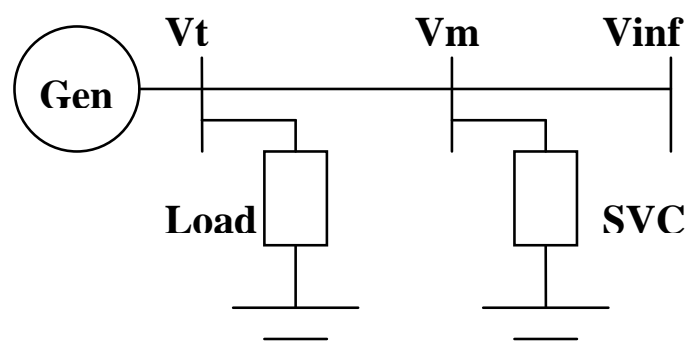

Fig. 1: Studied Power System With SVC.

\section{STUDIED SYSTEM MODELING}

\subsection{Generator Model}

A Two-Axis dynamic model [15] has been used in this study. The system dynamic Equations are given by:

$$
\begin{aligned}
\dot{\delta} & =\omega-\omega_{\mathrm{s}} \\
\mathrm{M} \dot{\omega} & =\mathrm{T}_{\mathrm{M}}-\left[\mathrm{E}_{\mathrm{q}}^{\backslash}-\mathrm{X}_{\mathrm{d}}^{\backslash} \mathrm{i}_{\mathrm{d}}\right] \mathrm{i}_{\mathrm{q}}-\left[\mathrm{E}_{\mathrm{d}}^{\backslash}-\mathrm{X}_{\mathrm{q}}^{\backslash} \mathrm{i}_{\mathrm{q}}\right] \mathrm{i}_{\mathrm{d}}-\mathrm{D}\left(\omega-\omega_{\mathrm{s}}\right) \\
\mathrm{T}_{\mathrm{do}}^{\backslash} E_{q}^{\backslash} & =-E_{q}^{\backslash}-\left(\mathrm{X}_{\mathrm{d}}-\mathrm{X}_{\mathrm{d}}^{\backslash}\right) \mathrm{i}_{\mathrm{d}}+\mathrm{E}_{\mathrm{fd}} \\
\mathrm{T}_{\mathrm{qo}}^{\backslash} E_{d}^{\backslash} & =-E_{d}^{\backslash}-\left(\mathrm{X}_{\mathrm{q}}-\mathrm{X}_{\mathrm{q}}^{\backslash}\right) \mathrm{i}_{\mathrm{q}}
\end{aligned}
$$

\subsection{Exciter Model}

In this study, The IEEE Type DC-1 Exciter [15] has been used. The dynamic equations for this exciter are given by: 


$$
\begin{aligned}
& T_{E} \dot{E}_{f d}=-\left(K_{E}+S_{E}\left(E_{f d}\right)\right) E_{f d}+V_{R} \\
& T_{A} \dot{V}_{R}=-V_{R}+K_{A} R_{f}-\frac{K_{A} K_{f}}{T_{f}} E_{f d}+K_{A}\left(V_{r e f}-V_{t}\right) \\
& T_{F} \dot{R}_{f}=-R_{f}+\frac{K_{f}}{T_{f}} E_{f d}
\end{aligned}
$$

\subsection{Static VAR Model}

The static Var compensator has many different models presented by literatures [5]. In this paper the used SVC is consisted of Fixed Capacitor and Thyristor Controlled reactor, ( FC-TCR) Type. The firing angle $\alpha$ of the reactor thyristor can be controlled using the proposed controller. It's currents are related to the firing angles by the following equations:

$$
\mathrm{I}_{\mathrm{L}}(\alpha)=\frac{\mathrm{V}(2 \pi-2 \alpha+\sin 2 \alpha)}{\pi \omega \mathrm{L}}
$$

where $\pi / 2 \leq \alpha \leq \pi$

$$
\mathrm{I}_{\mathrm{L}}(\sigma)=\frac{\mathrm{V}(\sigma-\sin \sigma)}{\pi \omega \mathrm{L}}
$$

From the above equation the reactor virtual susceptance can be expressed as:

$$
\mathrm{B}_{\mathrm{L}}(\sigma)=\frac{I_{L}(\sigma)}{V}
$$

from equations (9) and (10) the susceptance can be expressed as:

$$
\mathrm{B}_{\mathrm{L}}(\sigma)=\frac{\sigma-\sin \sigma}{\pi \omega \mathrm{L}}
$$

The overall SVC susceptance is given by the summation of the fixed capacitor susceptance and the thyristor controlled variable reactor susceptance, which expressed as:

$$
\mathrm{B}_{\mathrm{SVC}}=\mathrm{B}_{\mathrm{c}}+\mathrm{B}_{\mathrm{L}}(\sigma)
$$

\section{WAVELET NEURAL NETWORK CONTROLLER PRINCIPLES}

The present wavelet neural network, WNN controller which consists of four layer controller is discussed in [16]. The target of the controller is to track the speed deviations, and torque angle deviation to zero, in case of severe disturbance. To develop this controllers, two input error signals were selected, the first one is the speed deviation, which is taken as a tracking error, $\varepsilon_{1}$ and it's rate of change. The input of the 
WNN controller consists of the errors $\varepsilon_{1}, \varepsilon_{1}\left(1-\mathrm{z}^{-1}\right)$ with $\mathrm{z}^{-1}$ is the time delay. The output of the WNN will be added to the voltage regulator gain to form the angle $\alpha$.

\subsection{WNN Technique Analysis}

The signal propagation and the basic function in each ANN layer can be displayed in the following. For every node $i$ in the input layer, the net input and the net output can be described by the following equations:

$$
\text { net }_{i}^{1}=x_{i}^{1} \quad y_{i}^{1}=f_{i}^{1}\left(\text { net }_{i}^{1}\right)=\text { net }_{i}^{1}, \quad i=1,2
$$

where $x_{1}^{1}=\varepsilon$ and $x_{2}^{1}=\varepsilon\left(1-z^{-1}\right)$

The family of the wavelet is usually constructed by translation and dilations performed on a single fixed function, called the mother wavelet. In which layer, each node performs a wavelet $\Phi_{\mathrm{j}}$ that is derived from its "mother wavelet". The first derivative of a Gaussian function, is adopted as a mother wavelet in this study, and expressed as $\Phi(\mathrm{x})=-\mathrm{x} \exp \left(-\mathrm{x}^{2} / 2\right)$. For the $\mathrm{j}^{\text {th }}$ node

$$
\begin{aligned}
\text { net }_{\mathrm{j}}^{2} & =\left(\mathrm{x}_{\mathrm{i}}^{2}-\mathrm{m}_{\mathrm{ij}}\right) / \sigma_{\mathrm{ij}} \\
y_{j}^{2} & =f_{j}^{2}\left(\text { net }_{\mathrm{j}}^{2}\right)=\phi_{\mathrm{j}}\left(\text { net }_{\mathrm{j}}^{2}\right) \mathrm{j}=1, \ldots, \mathrm{n}
\end{aligned}
$$

Where $\mathrm{m}_{\mathrm{ij}}$ and $\sigma_{\mathrm{ij}}$ are the translation and dilation in the $\mathrm{j}^{\mathrm{th}}$ term of the $\mathrm{i}^{\mathrm{t}}$ input $x_{i}^{2}$ to the node of mother wavelet layer, and $n$ is the all number of wavelets with respect to the input nodes. Each node $\mathrm{k}$ in the wavelet layer is denoted by $\Pi$, which multiplies in the input signals and outputs result of the product[14]. Hence, for the $\mathrm{k}^{\text {th }}$ rule node

$$
\operatorname{net}_{\mathrm{k}}^{3}=\prod_{\mathrm{j}} \mathrm{w}_{\mathrm{jk}}^{3} \mathrm{x}_{\mathrm{j}}^{3}, \quad \mathrm{y}_{\mathrm{k}}^{3}=\mathrm{f}_{\mathrm{k}}^{3}\left(\text { net }_{\mathrm{k}}^{3}\right)=\text { net }_{\mathrm{k}}^{3}, \quad \mathrm{k}=1, \ldots, 1
$$

Where $x_{j}^{3}$ represents the $j^{\text {th }}$ input to the node of the wavelet layer, and $w_{j k}^{3}$ is the weights between the mother wavelet layer and the wavelet layer, and assumed to be unity. The number of the wavelet is given as $l=n / i$ if each input node has the same mother wavelet nodes. The $\Sigma$ is known as the single node 0 in the output layer, which compute the overall output as the summation of all input signals.

$$
\operatorname{net}_{\mathrm{o}}^{4}=\sum_{\mathrm{k}} \mathrm{k}_{\mathrm{ko}}^{4} \mathrm{x}_{\mathrm{k}}^{4} \mathrm{y}_{\mathrm{o}}^{4}=\mathrm{f}_{\mathrm{o}}^{4}\left(\operatorname{net}_{\mathrm{o}}^{4}\right)=\operatorname{net}_{\mathrm{o}}^{4}, \mathrm{o}=1
$$

Where the connecting weight $\mathrm{w}_{\mathrm{ko}}^{4}$ is the output action strength of the $\mathrm{O}^{\text {th }}$ output associated with the $\mathrm{k}^{\text {th }}$ wavelet, and $\mathrm{x}_{\mathrm{k}}^{4}$ represents the $\mathrm{k}^{\text {th }}$ input to the node of output layer,

and $y_{1}^{4}=\alpha$.

Hence the output signal of the controller is as given in the above equation. 


\subsection{On-line Training Algorithm for Wavelet Neural network}

The main part of the training algorithm is how to obtain a gradient vector in which each element in the training algorithm is defined as the derivative of the energy function with respect to the parameters of the network. This can be obtained by the chain rules, and the method is generally referred to as back propagation learning rules. In order to illustrate the on-line training mechanism of the WNN using the supervised gradient descent method, the energy function should firstly defined as $E=0.5 \mathrm{e}^{2}$. Hence, the on-line training mechanism, based on back propagation can be expressed as follows:

$$
\delta_{\mathrm{o}}^{4}=-\frac{\partial \mathrm{E}}{\partial \mathrm{y}_{\mathrm{o}}^{4}}=\left[-\frac{\partial \mathrm{E}}{\partial \varepsilon} \frac{\partial \varepsilon}{\partial \mathrm{y}_{\mathrm{o}}^{4}}\right]
$$

The weight $\Delta \mathrm{W}_{\mathrm{ko}}{ }^{4}$ can be updated by the equation

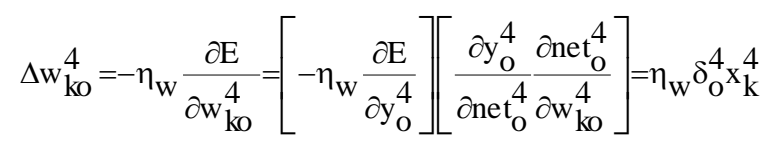

The weights of the layers are updated according to the following equation:

$$
\mathrm{w}_{\mathrm{ko}}^{4}(\mathrm{~N}+1)=\mathrm{w}_{\mathrm{ko}}^{4}(\mathrm{~N})+\Delta \mathrm{w}_{\mathrm{ko}}^{4}
$$

Where $\mathrm{N}$ is the iteration number and $\eta_{\mathrm{w}}$ is the weight learning rate.

The weights in the wavelet layer are unity, hence the error term needs to be calculated and propagated. The error term is then

$$
\delta_{\mathrm{k}}^{3}=-\frac{\partial \mathrm{E}}{\partial \mathrm{net}_{\mathrm{k}}^{3}}\left(-\frac{\partial \mathrm{E}}{\partial \mathrm{y}_{\mathrm{o}}^{4}}\right)\left(\frac{\partial \mathrm{y}_{\mathrm{o}}^{4}}{\partial \mathrm{net}_{\mathrm{o}}^{4}} \frac{\partial \mathrm{net}_{\mathrm{o}}^{4}}{\partial \mathrm{y}_{\mathrm{k}}^{3}} \frac{\partial \mathrm{y}_{\mathrm{k}}^{3}}{\partial \mathrm{net}_{\mathrm{k}}^{3}}\right)=\delta_{\mathrm{o}}^{4} \mathrm{w}_{\mathrm{ko}}^{4}
$$

The error term can be obtained by the following equation

$$
\begin{aligned}
\delta_{\mathrm{j}}^{2} & =-\frac{\partial \mathrm{E}}{\partial \mathrm{net}_{\mathrm{j}}^{2}} \\
& =\left(-\frac{\partial \mathrm{E}}{\partial \mathrm{y}_{\mathrm{o}}^{4}} \frac{\partial \mathrm{y}_{\mathrm{o}}^{4}}{\partial \mathrm{net}_{\mathrm{o}}^{4}} \frac{\partial \mathrm{net}_{\mathrm{o}}^{4}}{\partial \mathrm{y}_{\mathrm{k}}^{3}} \frac{\partial \mathrm{y}_{\mathrm{k}}^{3}}{\partial \mathrm{net}_{\mathrm{k}}^{3}}\right)\left(\frac{\partial \mathrm{net}_{\mathrm{k}}^{3}}{\partial \mathrm{y}_{\mathrm{j}}^{2}} \frac{\partial \mathrm{y}_{\mathrm{j}}^{2}}{\partial \mathrm{net}_{\mathrm{j}}^{2}}\right) \\
& =\sum_{\mathrm{k}} \delta_{\mathrm{k}}^{3} \mathrm{y}_{\mathrm{k}}^{3}
\end{aligned}
$$

The update rule of $\mathrm{m}_{\mathrm{ij}}$ is as follows:

$$
\Delta m_{i j}=-\eta_{m} \frac{\partial E}{\partial m_{i j}}=\left(-\eta_{m} \frac{\partial E}{\partial y_{j}^{2}} \frac{\partial y_{j}^{2}}{\partial n t_{j}^{2}} \frac{\partial n e t_{j}^{2}}{\partial m_{i j}}\right)=-\eta_{m} \frac{\delta_{j}^{2}}{\sigma_{i j}}
$$

The rule for updating $\sigma_{\mathrm{ij}}$ is as follows: 


$$
\begin{aligned}
\Delta \sigma_{i j} & =-\eta_{\sigma} \frac{\partial E}{\partial \sigma_{i j}}=\left(-\eta_{\sigma} \frac{\partial E}{\partial y_{j}^{2}} \frac{\partial y_{j}^{2}}{\partial n e t_{j}^{2}} \frac{\partial n e t_{j}^{2}}{\partial \sigma_{i j}}\right) \\
& =-\eta_{\sigma} \delta_{j}^{2} \frac{\left(m_{i j}-x_{i}^{2}\right)}{\left(\sigma_{i j}\right)^{2}}
\end{aligned}
$$

The dilation and translation of the mother wavelet can be updated as follows:

$$
\begin{gathered}
\mathrm{m}_{\mathrm{ij}}(\mathrm{N}+1)=\mathrm{m}_{\mathrm{ij}}(\mathrm{N})+\Delta \mathrm{m}_{\mathrm{ij}} \\
\sigma_{\mathrm{ij}}(\mathrm{N}+1)=\sigma_{\mathrm{ij}}(\mathrm{N})+\Delta \sigma_{\mathrm{ij}}
\end{gathered}
$$

Where $\eta_{\sigma}$ and $\eta_{\mathrm{m}}$ are the learning rates of the dilation and translation of the mother wavelet. To increase the on-line learning rate of the weights, the following approximation rule is adopted:

$$
\delta_{\mathrm{O}}^{4} \cong \varepsilon+\varepsilon\left(1-\mathrm{z}^{-1}\right)
$$

The values of the learning rates affect the network performance. In order to train the WNN effectively, adaptive learning rates, which assure the convergence of tracking error based on the analysis of a discrete type Lyapunov function. The convergence analysis in this study is to derive a specific learning rates for specific types of network parameters to assure convergence of the tracking error[20].

Assume $\eta_{\mathrm{w}}$ be the learning rate of the WNN weights and

$\mathrm{P}_{\mathrm{w} \max }=\max _{\mathrm{N}}\left\|\mathrm{P}_{\mathrm{W}}(\mathrm{N})\right\|$ with, $\mathrm{P}_{\mathrm{W}}(\mathrm{N})=\partial \mathrm{y}_{\mathrm{o}}^{4} / \partial \mathrm{w}_{\mathrm{ko}}^{4}$ and $\|\cdot\|$ is the education norm in $\mathrm{R}^{\mathrm{n}}$. The convergence is guaranteed if $\eta_{\mathrm{w}}$ is chosen as $\eta_{\mathrm{w}}=\lambda / \mathrm{P}_{\mathrm{w} \max }^{2}=\lambda / \mathrm{R}_{\mathrm{u}}$, in which $\lambda$ is a positive constant gain, and $R_{u}$ is the number of nodes in the wavelet layer of the WNN.

Since $\mathrm{P}_{\mathrm{W}}(\mathrm{N})=\partial \mathrm{y}_{\mathrm{o}}^{4} / \partial \mathrm{w}_{\mathrm{ko}}^{4}=\mathrm{x}_{\mathrm{k}}^{4}$, Then $\left\|\mathrm{P}_{\mathrm{W}}(\mathrm{N})\right\|<\sqrt{\mathrm{R}_{\mathrm{u}}}$. The discrete type lyapunov function is selected as: $\mathrm{V}(\mathrm{N})=\mathrm{e}^{2}(\mathrm{~N}) / 2$. The change in the lyapunov function is obtained by $\Delta \mathrm{V}(\mathrm{N})=\mathrm{V}(\mathrm{N}+1)-\mathrm{V}(\mathrm{N})=\left[\mathrm{e}^{2}(\mathrm{~N}+1)-\mathrm{e}^{2}(\mathrm{~N})\right] / 2$ Therefore, error difference can be expressed as:

$$
\mathrm{e}(\mathrm{N}+1)=\mathrm{e}(\mathrm{N})+\Delta \mathrm{e}(\mathrm{N})=\mathrm{e}(\mathrm{N})+\left[\frac{\partial \mathrm{e}(\mathrm{N})}{\partial \mathrm{w}_{\mathrm{ko}}^{4}}\right]^{\mathrm{T}} \Delta \mathrm{w}_{\mathrm{ko}}^{4}
$$

Where $\Delta \mathrm{w}_{\mathrm{ko}}^{4}$ represents a weight change in the output layer. Using Eqns. (19),(20) and (30) Then,

and

$$
\frac{\partial \mathrm{e}(\mathrm{N})}{\partial \mathrm{w}_{\mathrm{ko}}^{4}}=\frac{\partial \mathrm{e}(\mathrm{N})}{\partial \mathrm{y}_{\mathrm{o}}^{4}} \frac{\partial \mathrm{y}_{\mathrm{o}}^{4}}{\partial \mathrm{w}_{\mathrm{ko}}^{4}}=-\frac{\delta_{\mathrm{o}}^{4}}{\mathrm{e}(\mathrm{N})} \mathrm{P}_{\mathrm{w}}(\mathrm{N})
$$

$$
e(N+1)=e(N)-\left[\frac{\delta_{o}^{4}}{e(N)} P_{w}(N)\right]^{T} \eta_{w} \delta_{o}^{4} P_{w}(N)
$$

Hence 


$$
\mathrm{P}_{\mathrm{W}}(\mathrm{N})=\partial \mathrm{y}_{\mathrm{o}}^{4} / \partial \mathrm{w}_{\mathrm{ko}}^{4}=\mathrm{x}_{\mathrm{k}}^{4}
$$

Thus

$$
\begin{aligned}
\|\mathrm{e}(\mathrm{N}+1)\| & =\left\|\mathrm{e}(\mathrm{N})\left[1-\eta_{\mathrm{w}}\left[\delta_{\mathrm{o}}^{4} / \mathrm{e}(\mathrm{N})\right]^{2} \mathrm{P}_{\mathrm{w}}^{\mathrm{T}}(\mathrm{N}) \mathrm{P}_{\mathrm{w}}(\mathrm{N})\right]\right\| \\
& \leq\|\mathrm{e}(\mathrm{N})\|\left\|1-\eta_{\mathrm{w}}\left[\delta_{\mathrm{o}}^{4} / \mathrm{e}(\mathrm{N})\right]^{2} \mathrm{P}_{\mathrm{w}}^{\mathrm{T}}(\mathrm{N}) \mathrm{P}_{\mathrm{w}}(\mathrm{N})\right\|
\end{aligned}
$$

If $\eta_{\mathrm{w}}$ is chosen as $\eta_{\mathrm{w}}=\lambda / \mathrm{P}_{\mathrm{w} \max }^{2}=\lambda / \mathrm{R}_{\mathrm{u}}$, The term $\| 1-\eta_{\mathrm{w}}$ $\left[\delta_{\mathrm{o}}^{4} / \mathrm{e}(\mathrm{N})\right]^{2} \mathrm{P}_{\mathrm{w}}^{\mathrm{T}}(\mathrm{N}) \mathrm{P}_{\mathrm{w}}(\mathrm{N}) \|$ in the above Eq. Is less than 1. Therefore, the Lyapunov stability of $\Delta \mathrm{V}>0$ and $\Delta \mathrm{V}<0$ is guaranteed. The tracking error will converge to zero when $\mathrm{t} \rightarrow \infty$.

\section{DESIGN OF WNN STATIC VAR COMPENSATOR CONTROLLER}

The present WNN static Var compensator controller implements two input signals the speed deviation and rate of change of speed deviations. The output wavelet neural network static Var compensator controller signal is $\alpha$. The schematic diagram of such WNN static Var compensator controller is given in Fig. 2.

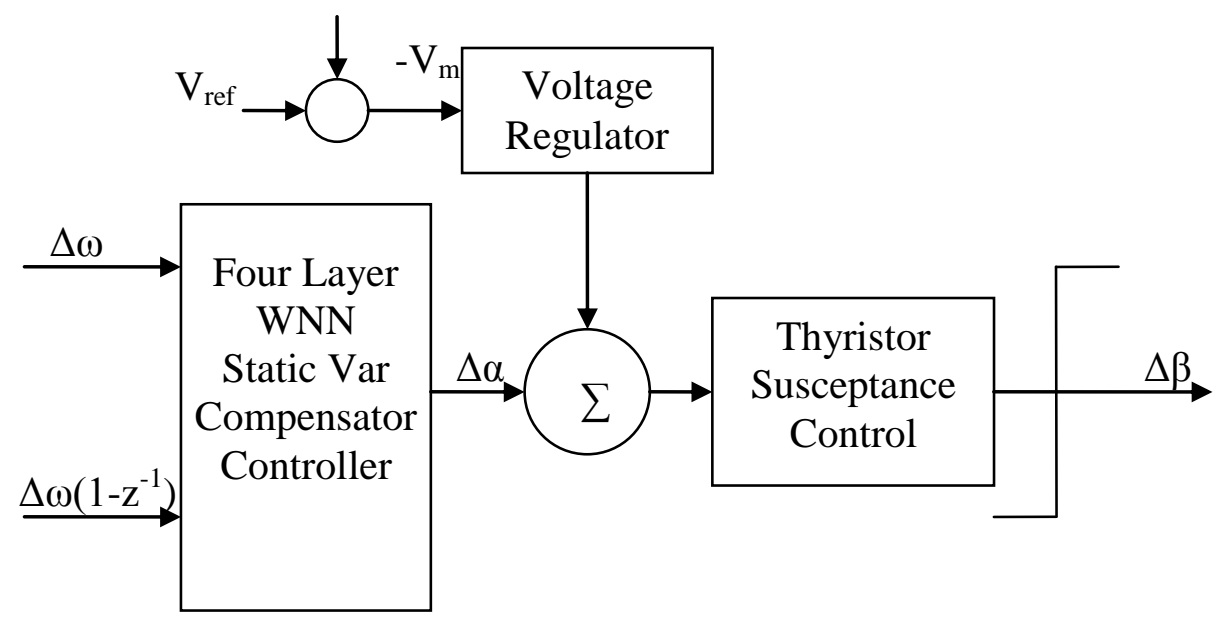

Fig. 2: Schematic diagram for the proposed WNN Static Var Compensator Controller.

\section{DIGITAL SIMULATION RESULTS}

\subsection{Study Methodology}

The superiority of the proposed WNN controller can be indicated by considering two different disturbances for two different operating conditions, and the studied power system responses are obtained. A comparative study between the proposed WNN static var compensator controller and the conventional proportional plus integral PI controller are performed and the results are discussed. 


\subsubsection{Application of three-phase short circuit fault}

Figures 3 and 4 depicts the studied system response, with the proposed WNN controller and conventional PI controller when a three-phase to ground short circuit fault is considered at the generator terminal for $100 \mathrm{~m}$. sec. The damping effect of the proposed WNN static var compensator controller over the conventional PI static var compensator controller is evident. The proposed WNN controller has a very fast response, with less overshoot and undershoot.
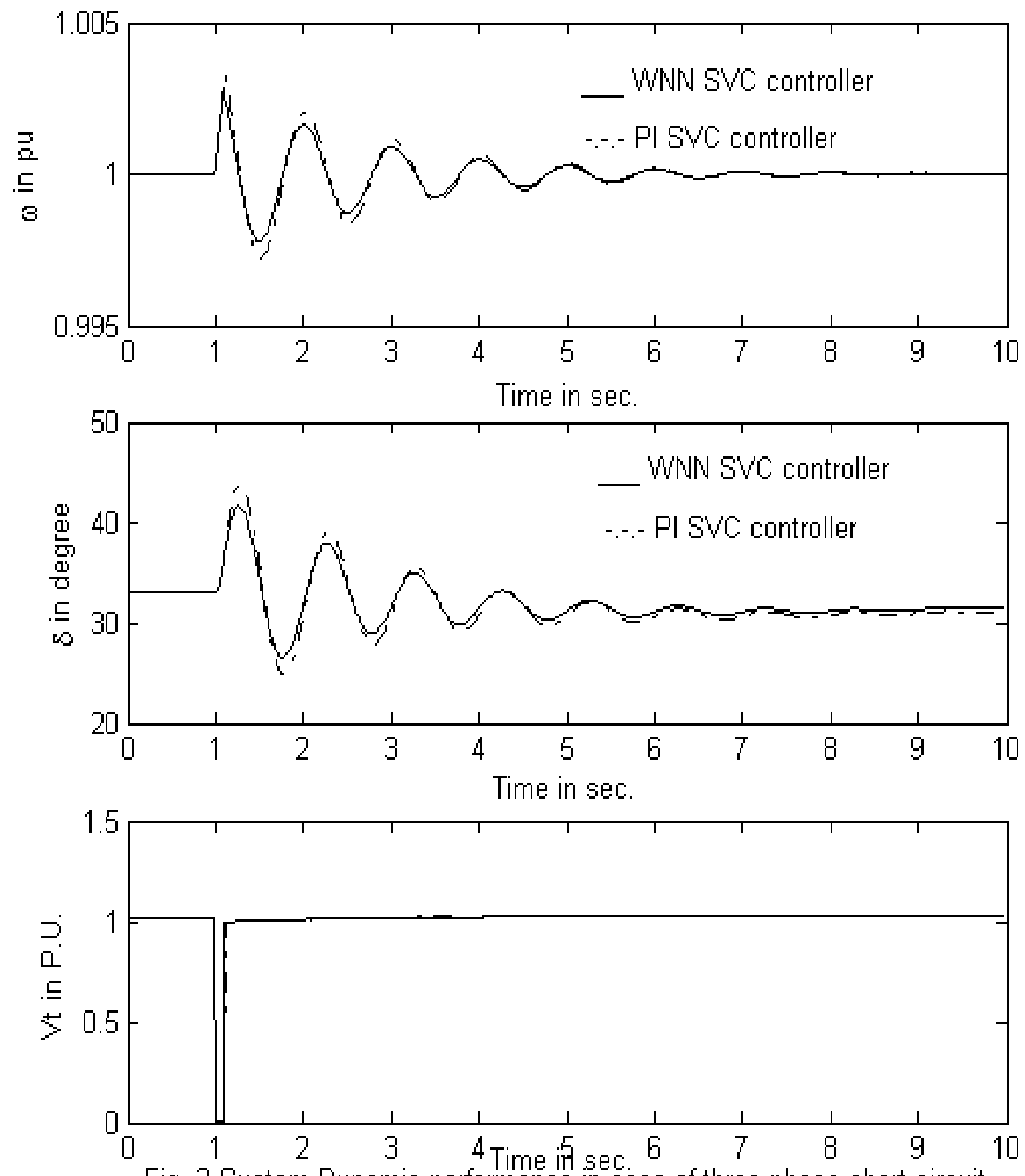

Fig. 3 System Dynamic performance in case of three phase short circuit fault with the proposed WNN SVC controller and PI SVC controller $\mathrm{p}=1.0 \mathrm{p} . \mathrm{Q} \mathrm{Q}=0.05 \mathrm{p} . \mathrm{U}$ 

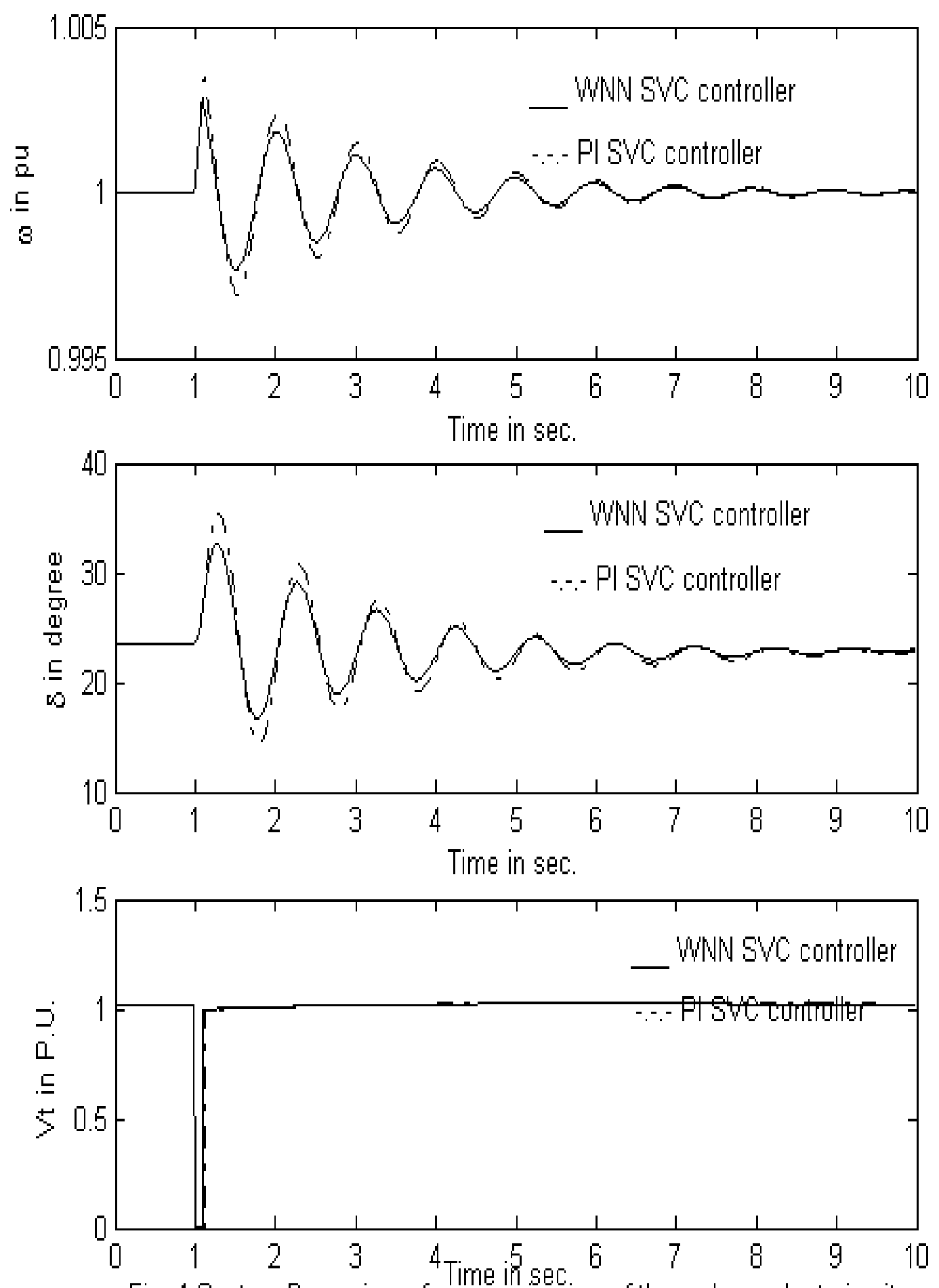

Fig. 4 System Dynamic performance in case of three phase short circuit fault with the proposed WNN SVC controller and PI SVC controller $p=1.0 \mathrm{p} . u \mathrm{Q}=0.5 \mathrm{p} . \mathrm{u}$ 


\subsubsection{Application of Input mechanical power disturbance}

Figures 5 and $\mathbf{6}$ show the studied system response when the generator is subjected to input mechanical power disturbance with SVC based WNN controller and SVC based PI controller. The damping effect of the SVC based WNN controller over the conventional PI controller is obtained. The proposed SVC based WNN controller has a very fast response with a very good damping adding to less overshoot and undershoot with better control quality.
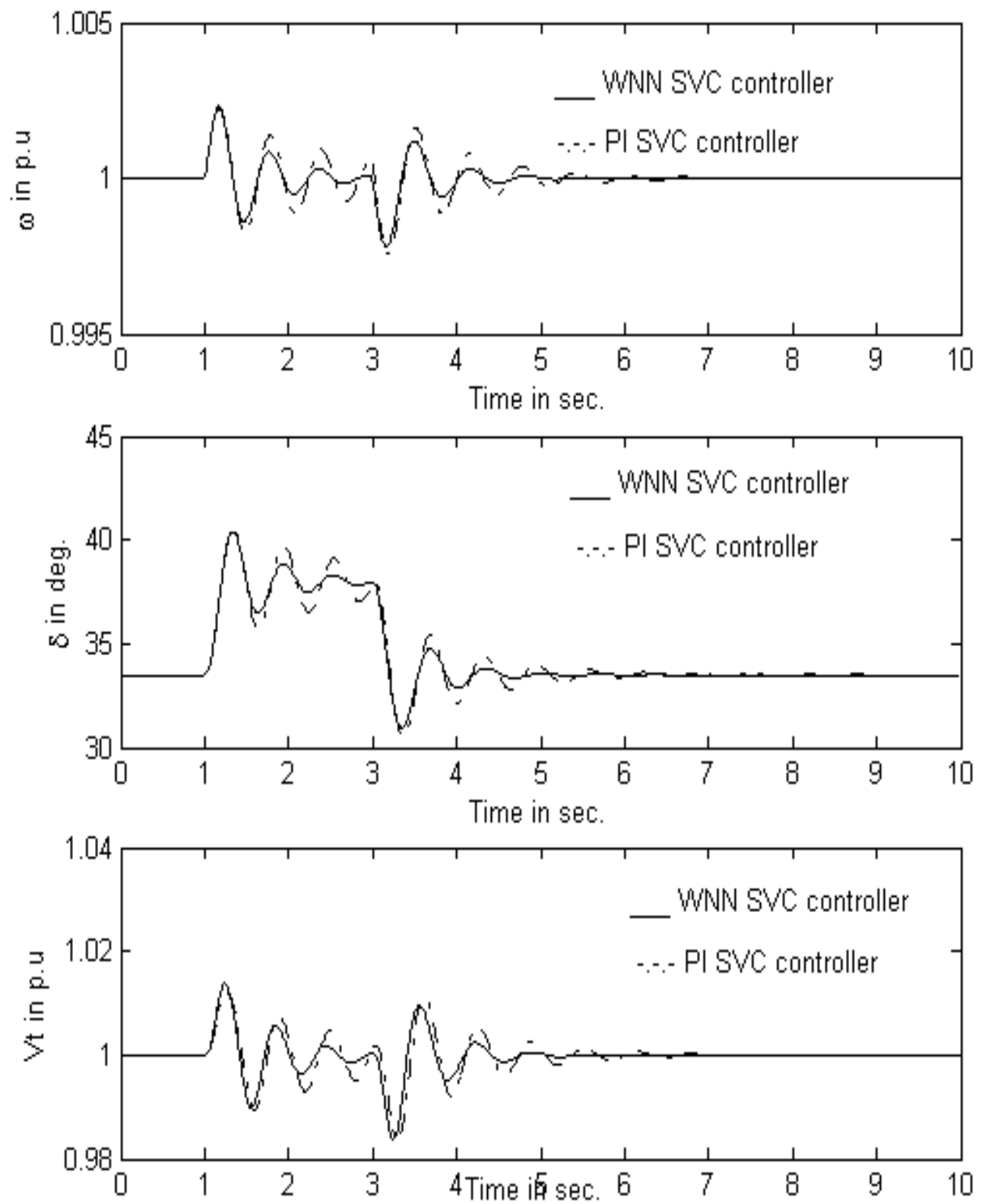

Fig. 5 System Dynamic performance in case of torque step disturbance fault with the proposed WNN SVC controller and PI SVC controller $p=1.0 p . u Q=0.05 p . u$ 

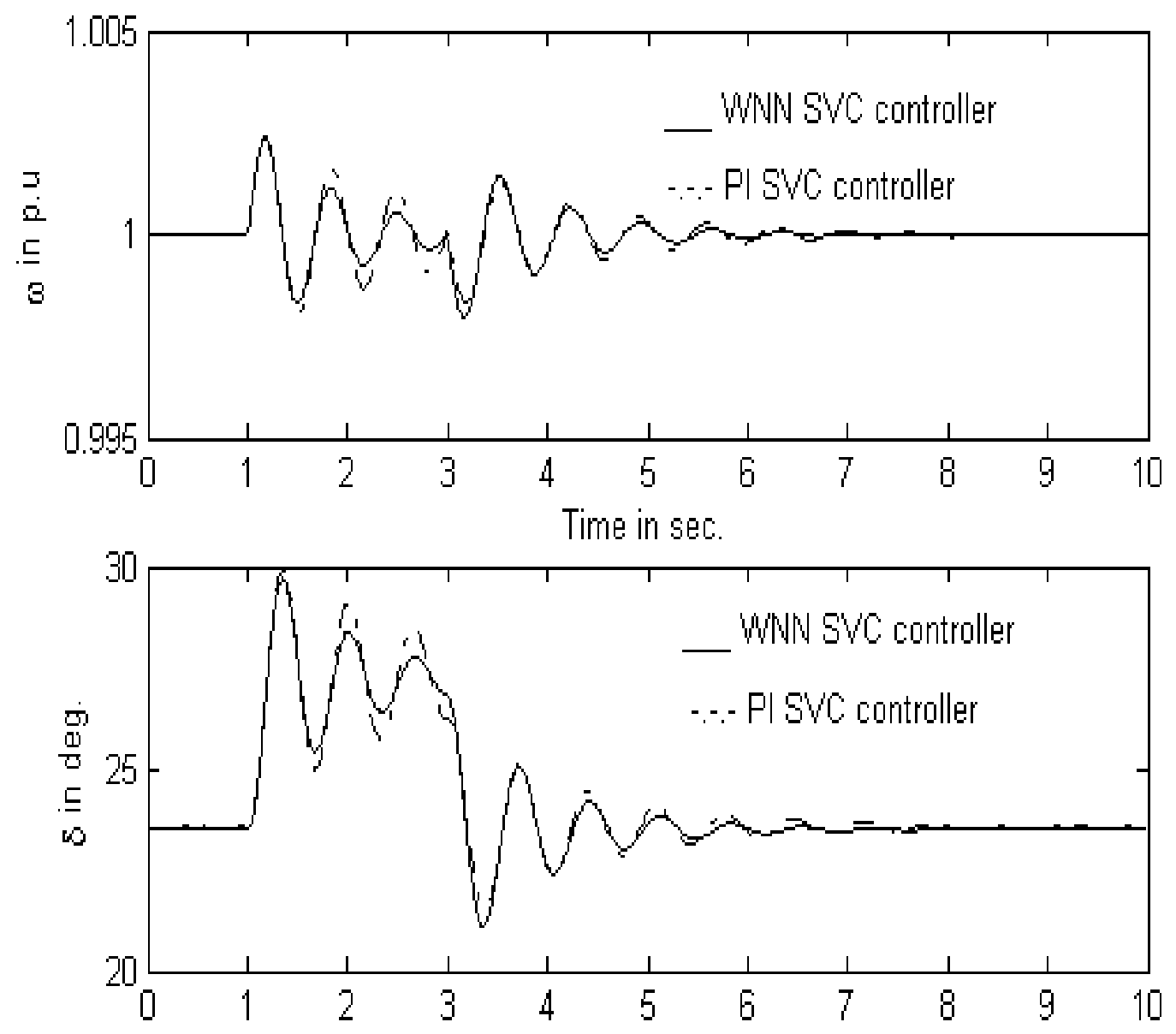

Time in sec.

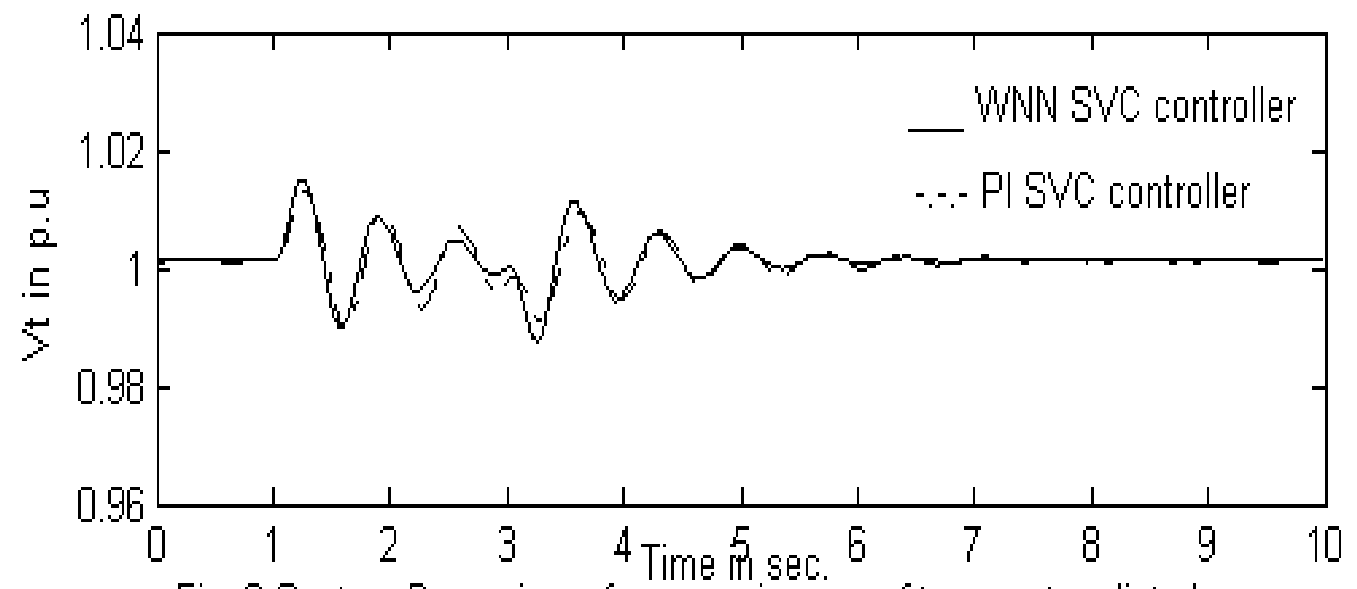

Fig. 6 System Dynamic performance in case of torque step disturbance fault with the proposed WNN SVC controller and PI SVC controller $\mathrm{p}=1.0 \mathrm{p} . \mathrm{Q} \mathrm{Q}=0.5 \mathrm{p}$.U 


\section{CONCLUSIONS}

Wavelet neural network, WNN control technique has been used with SVC to improve the dynamic performance of the power system in case of abnormal conditions. The proposed control technique train the neural network on line and obtain a variable control parameters based on time simulation of the studied power system. The proposed WNN controller has established to provide a very fast response and better control quality.

To evaluate the effectiveness of the WNN SVC controller two different disturbances was considered with different operating conditions. The time simulation results prove the superiority of the WNN controller over the PI controller with very fast response and very good damping.

\section{REFERENCES}

[1] M. Z. El Sadek, " Prevention Measure for Voltage Collapses and Voltage Failure in The Egyptian Power Systems," Electric Power Systems Research Journal, Vol. 44, 1988, pp. 203-211

[2] Slaven Kincic, et al "Voltage Support by Distributed Static VAR Systems (SVS)" IEEE Trans. On Power Delivery, Vol. 2, No. 2, April, 2005, pp. 1541-1549.

[3] Thomas L. Baldwin, at al, "Reactive-Power Compensation for Voltage Control at Resistance Welders" IEEE Trans. On Industry Applications, Vol. 41, No. 6, Nov./Dec. 2005, pp. 1485-1492.

[4] Jimmie J. Cathey, Wilda E. Moore," Improvement of generator output and stability margin by use of a dedicated static VAR compensator" Electric Power Systems Research Journal, Vol. 63 (2002) pp. 119-125.

[5] Gaber El-Saady, "Adaptive Static VAR Controller For Simultaneous Elimination of Voltage Flickers and Phase Current Imbalances Due to ARC Furnaces Loads," Proceedings of $3^{\text {rd }}$ Int. Conf. On Eng. Research, Nov. 1999, Vol. 1, pp 63-73.

[6] M. K. Verma, S. C. Srivastava, "Optimal Placement of SVC for Static and Dynamic Voltage Security Enhancement" International Journal of Emerging Electric Power Systems Volume 2, Issue 2, 2005 Article 1050.

[7] A.H.M.A. Rahim, E.P. Nowicki, O.P. Malik, "Enhancement of power system dynamic performance through an on-line self-tuning adaptive SVC controller" Electric Power Systems Research Journal (76) 2006, pp. 801-807

[8] A M Sharaf, M Z El-Sadek, F N Abd-Elbar and A M Hemeida,"A Global Dynamic Error Driven Control Scheme For Static VAR Compensators", Electric Power Systems Research Journal, Vol. 51, 1999, pp.131-141.

[9] M.Z. El-Sadek, G. El-Saady, M. Abo-El-Saud, A variable structure adaptive neural network static VAR controller, Electr. Power Syst. Res. 45 (1998), pp. 109-117.

[10] Takashi Hiyama, Walid Hubbi, Thomas H. Ortmeyer, " Fuzzy Logic Control Scheme with Variable Gain for Static Var Compensator to Enhance Power System Stability" IEEE Transactions on Power Systems, Vol. 14, No. 1, February 1999, pp. 186-191.

[11] K. Ellithy,"A hybrid Neurofuzzy static var compensator stabilizer for power system damping improvement in the presence of load parameters uncertainty," Electric Power Systems Research Journal, 56, 2000, pp. 211-223. 
[12] P. K. Dash and S. Mishra, "Damping of multimodal power system oscillations by FACTS devices using non-linear Takagi-Sugeno fuzzy controller" International Journal of Electrical Power \& Energy Systems, Volume 25, Issue 6, July 2003, pp. 481-490.

[13] Ying-Tung Hsiao*, Chia-Hong Chen, Cheng-Chih Chien, "Optimal capacitor placement in distribution systems using a combination fuzzy-GA method" International Journal Electrical Power and Energy Systems Vol. 26 (2004), pp. 501-508

[14] A. M. Hemeida, "Wavelet Neurofuzzy Controller For Enhancememnt of Multimachine Power System Stability",The Journal of Engineering Science, Faculty of Engineering, Assuit University, Assiut, Egypt, Vol. 33, No. 2, March 2005, pp. 583-597.

[15] P. Anderson, and A. A. Fouad, "Power System Control and Stability," Book, IEEE Press, N.Y. 1994.

[16] A. M. Hemeida, "Wavelet Neural Network Load Frequency Controller", International Journal of Energy Conversion and Management, Vol. 46, Issue 9/10, 2005, pp. 1613-1630

\section{محكمات الخلايا العصبية الموجية للتحكم في معوضات القدرة الإستاتيزة}

يقدم البحث تطبيق محكمـات الخلايـا العصبية الموجيـة للتحكم في معوضـات القدرة الغير فعالة

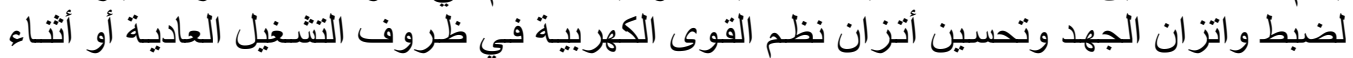

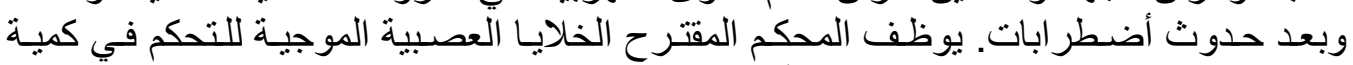
القدرة الغير فعالة المسحوبة من الثبكة أو التي يجب تزويد الثبكة بها. المحكم المقترح يوظف

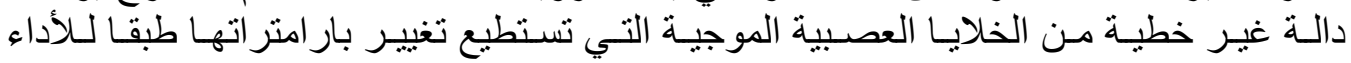

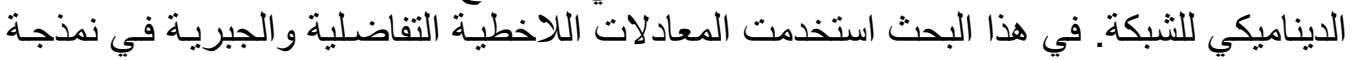

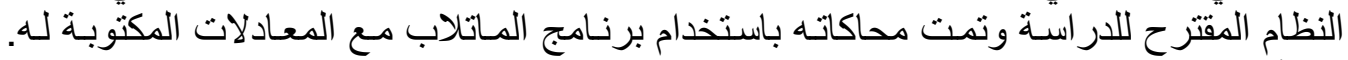
وقد أثبتت النتائج تفوق المحكم المقترح على التقليدي من حيث الكفاءة وسر عة الاستجابة و إخماد الاهتز از ات سريعا. 